Revista de Economia Política, vol. 31, nº 1 (121), pp. 98-117 janeiro-março/2011

\title{
Leigos, expertos e formação de expectativa
}

\section{LUIZ ROGÉRIO DE CAMARGOS*}

Laypeople, experts and expectation formation. This article is a critical discussion, under the light of expectation formation, of the relation that interposes between economic science as body of knowledge and its agents.

Keywords: expectation; rational expectation; methodological individualism; reflexive modernity; economic knowledge; social network.

JEL Classification: A14; B4; D84.

\section{INTRODUÇÃO}

Num estudo sobre a emergência da probabilidade, que surge com Pascal por volta de 1660, Hacking (1975) examina porque não há matemática conhecida sobre casualidade até a Renascença, embora jogos de azar sejam um dos mais antigos passatempos. Nesta época, segundo o autor, "probabilidade" era associada com a autoridade de quem disse o que, não com a evidência sobre o que foi realmente dito ou apresentado. O conceito de probabilidade moderna emergiu, de acordo com Hacking (ibid., p. 35), quando a opinião foi substituída pela evidência. Este conceito não existia até o final da Renascença: foi produto das "ciências inferiores", tais como medicina e alquimia que, por sua natureza, não poderiam prover provas demonstrativas, recorrendo a "sinais", que foram posteriormente reinterpretados pela ideia da evidência indutiva das coisas.

Em grande medida, como apontado por Lawson (1988), a literatura recente associa incerteza e expectativa econômica a uma noção particular de probabilidade. Podemos identificar duas posições opostas neste debate. Para

\footnotetext{
* Departamento de Economia da Universidade Federal de Sergipe. E-mail: rogeriocamargos@uol.com.br. As sugestões dos professores Marcos Fernandes Gonçalves da Silva, Robert Nicol, Ramón Fernandez e Eleutério Prado e de um parecerista anônimo contribuíram para aperfeiçoar este texto. A responsabilidade pelas idéias aqui discutidas é apenas do autor. Submetido: Julho 2008; Aprovado: Maio 2009.
} 
autores pós-keynesianos, como Lawson (1988; 1995) e Davidson (1982-3; 1991), as regras de probabilidade se aplicam apenas num mundo idealizado; para proponentes das expectativas racionais, como Lucas (1977), fazer uso prático de teoria econômica requer que se saiba quais distribuições de probabilidade os agentes estão utilizando.

Ironicamente, o fio condutor da reflexão que estamos propondo sobre formação de expectativa, afasta-se desse debate entre refutar ou conciliar probabilidade-incerteza-expectativa, estando mais próximo da significação primitiva de probabilidade: o significado dos termos "provável" e "probabilidade" eram atributos de opinião, em contraste com conhecimento, que somente poderia ser obtido pela demonstração. Assim, quanto mais representativa a autoridade, tanto mais provável seria a opinião (Hacking, 1975, p. 35).

Argumentamos que expectativa econômica é conhecimento socialmente construído a partir de expectativas de expertos, estando, em grande medida, disponíveis ao público através da mídia, e sendo rotineiramente incorporadas pelo leigo, ainda que de maneira diferenciada, à sua consciência prática. (Diga-se de passagem: pessoas comuns ou leigas somos todos nós; ninguém consegue ser perito em mais que uma porção mínima do conhecimento disponível).

\section{PROBABILIDADE, INCERTEZA E EXPECTATIVA}

$\mathrm{Na}$ forma sucinta, segue uma taxionomia para diferentes concepções de incerteza e probabilidade, proposta por Lawson (1988, p. 48). Como mostra a Tabela 1, a incerteza se classifica, probabilisticamente, como mensurável ou imensurável.

Tabela 1

\begin{tabular}{|c|c|c|}
\hline & $\begin{array}{c}\text { Probabilidade é uma prioridade } \\
\text { do conhecimento ou crença }\end{array}$ & $\begin{array}{c}\text { Probabilidade é tanto um } \\
\text { objeto do conhecimento } \\
\text { quanto uma propriedade } \\
\text { da realidade externa }\end{array}$ \\
\hline $\begin{array}{l}\text { Incerteza corresponde a uma } \\
\text { situação onde a probabilidade } \\
\text { é numericamente mensurável }\end{array}$ & $\begin{array}{c}\text { Subjetivistas } \\
\text { (ex. Savage, Friedman) }\end{array}$ & $\begin{array}{c}\text { Proponentes das } \\
\text { expectativas racionais } \\
\text { (ex. Muth, Lucas) }\end{array}$ \\
\hline $\begin{array}{l}\text { Incerteza corresponde a uma } \\
\text { situação onde a probabilidade } \\
\text { é numericamente imensurável }\end{array}$ & Keynes & Knight \\
\hline
\end{tabular}

O conceito de probabilidade, desde sua emergência, foi reconhecido como essencialmente dual pelos filósofos (Hacking, 1975, p. 13). Por um lado, o aspecto epistêmico, onde probabilidades são crenças que os agentes mantêm sobre o mundo, ou seja, uma forma de conhecimento. Nessa abordagem, duas escolas de pensamento, hoje em dia, são dominantes: a primeira, denominada de teoria lógica ou a priori de probabilidade, cujo precursor é Keynes (1921); 
a segunda, teoria subjetivista de probabilidade, interpreta a teoria matemática de probabilidade como o grau de crença numa hipótese ou evento, mantido por um indivíduo racional, em algum ponto específico do tempo.

$\mathrm{Na}$ segunda abordagem, probabilidades existem como parte da realidade externa, tendo existência objetiva, que é evidenciada por algum arranjo experimental ou natural. Sua principal corrente é a teoria frequencialista de probabilidade e se baseia na ideia empírica de que muitos fenômenos na natureza parecem ter frequências relativas estáveis.

Keynes, assim como Knight, argumenta que é relevante distinguir entre situações onde a incerteza pode ser medida, e aquelas onde isto não é possível. Entretanto Keynes, ao contrário de Knight, baseou sua visão num conceito original e lógico de probabilidade. Para Keynes, probabilidade é o grau de crença sobre uma relação lógica, construída a partir de um conjunto de proposições (conclusão), e outro de preposições (premissas). É também objetiva - e não subjetiva - "porque está envolvida com o grau de crença que é racional manter sob certas condições dadas, e não meramente sob crenças correntes de indivíduos particulares que podem ou não serem racionais" (Keynes, 1973, p. 4). Neste conceito de probabilidade como grau de crença, probabilidades não são necessariamente numéricas; nem mesmo comparáveis. Knight fundou sua teoria de incerteza e risco sob a interpretação frequencialista de probabilidade e, potencialmente, mesmo os eventos incertos poderiam ser reduzidos a medidas de risco (Perlman \& McCann, 1996).

Embora expectativa seja uma ideia central à ciência econômica nos dias de hoje, sua introdução na análise econômica é relativamente recente: Myrdal (1927) e, posteriormente, outros integrantes da Escola Sueca, foram pioneiros na inclusão de expectativas como variáveis explícitas num esquema de análise (Hansson, 1998, p. 503). Entretanto, foi Keynes que lhe conferiu status definitivo. Dois dos três principais determinantes da demanda agregada na análise de Keynes - investimento e preferência pela liquidez — dependem, essencialmente, das expectativas dos agentes. Entre 1960 e início dos anos 1970, grande parte dos modelos macroeconômicos, principalmente aqueles focados no estudo de inflação, utilizaram a premissa de expectativa adaptativa: o valor futuro de uma variável será uma função de seus valores passados (Laidler \& Parkin, 1975). A introdução de expectativas racionais, ocorrida no início da década de 1970, é um marco da abordagem dominante nos modelos macroeconômicos, desde então.

\section{Expectativas racionais}

Do ponto de vista teórico, a principal crítica à expectativa adaptativa orientou-se à sua falha em não assegurar duas condições inerentes a qualquer teoria de formação de expectativas: não é razoável admitir que as pessoas cometam, sistematicamente, os mesmos erros, nem que ignorem informações valiosas quando formam suas crenças. Muth (1961) foi o primeiro a formalizar 
estas críticas, introduzindo a hipótese da expectativa racional (HER), que se apoia na seguinte intuição: as variáveis econômicas são geradas por processos sistemáticos. Valendo-se de toda informação disponível, os agentes, ao longo do tempo, aprendem qual processo gera que variável, e utilizam este conhecimento para formar expectativas sobre aquela variável. A formulação da expectativa racional é comumente descrita como:

$$
{ }_{t-1} X_{t}^{e}=E\left[X_{t} \mid I_{t-1}\right]
$$

onde a expectativa de $\mathrm{X}$, formada no tempo $\mathrm{t}-1$, é a expectativa matemática de $\mathrm{X}$, condicional a toda informação disponível em $\mathrm{t}-1$. O conjunto de informação $I_{t-1}$ consiste do próprio modelo e de suas respectivas variáveis. Ou seja: as expectativas dos agentes, num modelo, equivalem à solução matemática do modelo. É por isso que a HER é referida como modelo consistente: se a expectativa difere da solução, ou a teoria está errada, ou o agente falha em usar toda a informação disponível.

Embora as expectativas racionais tenham sido a abordagem dominante na forma de pensar a dinâmica e avaliação de políticas na economia nos últimos trinta anos, vários problemas foram igualmente identificados. Do ponto de vista teórico, muitos modelos apresentam múltiplos equilíbrios. Do lado empírico, estão bem documentadas falhas da HER em explicar diversos fatos estilizados. Ball (1994) mostra que, sob a HER, políticas críveis de desinflação causam boom, ao invés de recessão. Outros trabalhos mostram que a HER não consegue explicar por que a inflação é tão persistente (Fuher \& Moore, 1995), ou o efeito retardado e gradual sobre a inflação devido a choques monetários (Mankiw, 2001). Em razão destes problemas, vários autores têm proposto o relaxamento de algumas premissas da HER ou, até mesmo, alternativas radicalmente diferentes no tratamento de expectativas nos modelos econômicos. Calvo (1983), Ball (2000), Sims (2001), Mankiw \& Reis (2001), Calvo et al. (2003), Woodford (2003), por exemplo, relaxam a premissa de informação perfeita. Alternativas mais radicais desvinculam a relação rígida entre modelo e expectativas dos agentes (Carroll, 2003; Frydman \& Goldberg, 2003).

"Por que os economistas abraçaram as expectativas racionais (Sargent, 1995 , p. 7)?” De fato, como apontado pelo autor, a HER tem características bastante atrativas. Recapitulando: $\left\{\right.$ expectativa do agente $\left.={ }_{t-1} X_{t}^{e}\right\}=\left\{E\left[X_{t} \mid I_{t}\right]\right.$ expectativa condicional verdadeira\}, onde: i) as expectativas incorporam todas as informações disponíveis e relevantes ao agente; ii) a formação da expectativa subentende uma visão de mundo, contida no modelo adotado pelo agente (modelo consistente); iii) as expectativas não são, sistematicamente, sobre-estimadas nem subestimadas (expectativa do erro esperado zero). Em particular, a definição da HER subentende que as expectativas dos agentes são consistentes com suas percepções e seu conhecimento acerca do mundo. Entretanto, a construção e utilização de modelos econômicos para descrever a realidade, resultam da disputa entre especialistas. Pode existir abordagem predominante, 
mas não há consenso sobre que modelo descreve "verdadeiramente" a economia. Por outro, a inclusão de expectativas nos mesmos, é desafio ainda maior. Primeiro: quais são, de fato, as expectativas relevantes aos agentes? Segundo: como estas expectativas são formadas? Sob a hipótese das expectativas racionais, as expectativas são determinadas a partir do próprio modelo. Mas postular que os agentes formam suas expectativas solucionando o modelo, é reduzir as expectativas daqueles à do próprio economista, quando a questão-chave é justamente entender as expectativas dos agentes.

Grande parte das soluções alternativas à HER, direta ou indiretamente, desvia-se da premissa (i). Embora os modelos de aprendizagem-padrão relaxem a condição (ii), retêm o princípio de que os agentes aprendem, e formam suas expectativas, tendo, como base, a estrutura de um modelo comum. De outra forma: todos utilizam instrumentos e conhecimentos especializados para formar suas expectativas; ao agente é suposto saber. Mas principalmente, e talvez seja esta a questão de fundo, a microfundamentação que caracteriza os modelos discutidos subentende uma explanação individualista. Em minucioso estudo sobre explanações individualistas e não individualistas, Bhargava (1992) diz que há muitas maneiras de formular as diferenças entre elas; porém, em última instância, "para os individualistas, as capacidades básicas que transformam um organismo biológico individual num ser humano, podem ser alcançadas desconsiderando interações específicas com os outros. Por outro lado, para os não individualistas, o indivíduo biológico é radicalmente incompleto como ser humano, e necessariamente requer tipos específicos de relações sociais para a formação e sustentação daquelas capacidades" (ibid., p. 11).

\section{FUNDAMENTOS PARA UMA TEORIA DE EXPECTATIVA ECONÔMICA}

\section{Introdução: visão individualista}

A visão individualista, ou doutrina do individualismo metodológico ${ }^{1}$ (doravante referido como IM), é vista, atualmente, como tendo três componentes: o individualismo explanatório (IE), que postula que todo fenômeno social deve ser explanado nos termos dos indivíduos e de suas propriedades; o individualismo ontológico (IO), que pressupõe que somente os indivíduos e suas propriedades existem, e todas as entidades e propriedades sociais podem ser reduzidamente identificadas; e o individualismo semântico (IS), que defende que o significado das palavras relacionadas a entidades sociais - ou frases que contenham predicados sociais - pode ser reduzido ao significado dos vocábulos, remetendo a entidades ou frases que contenham somente predicados individuais (Bhargava, 1992, pp. 19-22)

\footnotetext{
${ }^{1}$ A teoria da escolha racional, pilar da economia neoclássica, pressupõe o individualismo metodológico.
} 
Com o intuito de trazer alguma ordem na discussão do IM, ao afirmar que "existe ampla concordância no meio acadêmico de que o individualismo metodológico nunca foi enunciado com clareza suficiente a permitir sua própria avaliação", Bhargava inicia seu trabalho com uma exposição clara das diferentes ramificações dentro do IM, identificando suas razões e variantes mais importantes.

Das cinco versões propostas para o IE, três são classificadas como pertencendo ao modelo dedutivo-nomológico (D-N) de explanação; o adjetivo "dedutivo" é autoexplicativo; o "nomológico" implica que a generalização deve ser uma lei; as duas outras versões do IE, classificadas como intencionistas, não são nem dedutivas nem nomológicas. De acordo com o modelo D-N, uma das exigências formais da explanação diz que ela deve constituir um "argumento, no sentido técnico de ser uma inferência lógica, na qual o enunciado do que é para ser explanado, o explanandum, se deduza de um conjunto de, pelo menos, duas premissas, os explanans, uma das quais consiste das condições iniciais e, a outra, de uma generalização" (ibid., p. 22).

Em sua crítica ao IM, o autor aponta problemas graves nas condições impostas à estrutura explanatória das versões acima. Por exemplo: somente em casos muito particulares podemos supor a existência de leis na ciência social, ${ }^{2}$ comprometendo, assim, o modelo D-N. Quanto à perspectiva intencionista, a mais plausível segundo o autor, vamos examiná-la com mais detalhes.

\section{Intencionismo versus Contextualismo}

Segundo Bhargava, a visão intencionista pressupõe que a ação deve ser explicada em termos de crenças, havendo três asserções básicas sobre elas: primeiro, que elas existem; segundo, em conformidade com a perspectiva individualista, crenças existem apenas como estados internos dos indivíduos, não estando embutidas em ações ou quaisquer outras práticas; terceiro, que é a característica crucial de um estado intencional: crenças têm, necessariamente, conteúdo representacional, sendo objetivamente apreendidas através de seu conteúdo linguístico. Segue-se daí que a compreensão das crenças envolve a apreensão deste conteúdo, ou o entendimento do significado das palavras que o expressam.

Bhargava contesta a premissa individualista, argumentando que palavras-significados têm caráter irremediavelmente social. Nesta perspectiva, denominada pelo autor de contextualismo,

os conceitos devem ser entendidos em seu contexto social, e a fortiori, que eles são sociais no sentido de que são somente possíveis e susten-

\footnotetext{
${ }^{2}$ Sobre a inexistência de leis empíricas da ação humana, ver Bhargava (1992); sobre inexistência de leis teóricas, ver Rosenberg (1980).
} 
táveis num contexto social. Para o contextualista, conceitos não podem e não existem apenas nas mentes dos indivíduos, e apreendê-los não pode ser simplesmente uma questão de perfazer um ato individual. [...] seu compartilhamento não é alguma coisa que acontece contingentemente após eles terem sido formados ou apreendidos. A emergência e persistência dos significados não podem ser explicadas em termos de decisão individual ou conveniência entre indivíduos. [...] A referência do dia a dia é fixada pela prática e, consequentemente, é uma construção social ao invés de individual (ibid., p. 197).

Uma hipótese da teoria de significados discutida pelo autor, expressa a ideia básica que estaremos analisando nesta seção: interdependência entre leigos e expertos. Denominada por hipótese da divisão de trabalho linguístico, distingue dois grupos de pessoas, comuns e expertos, caracterizando o significado de um termo segundo a representação sugerida por Bhargava (ibid., p. 194):

Figura 1

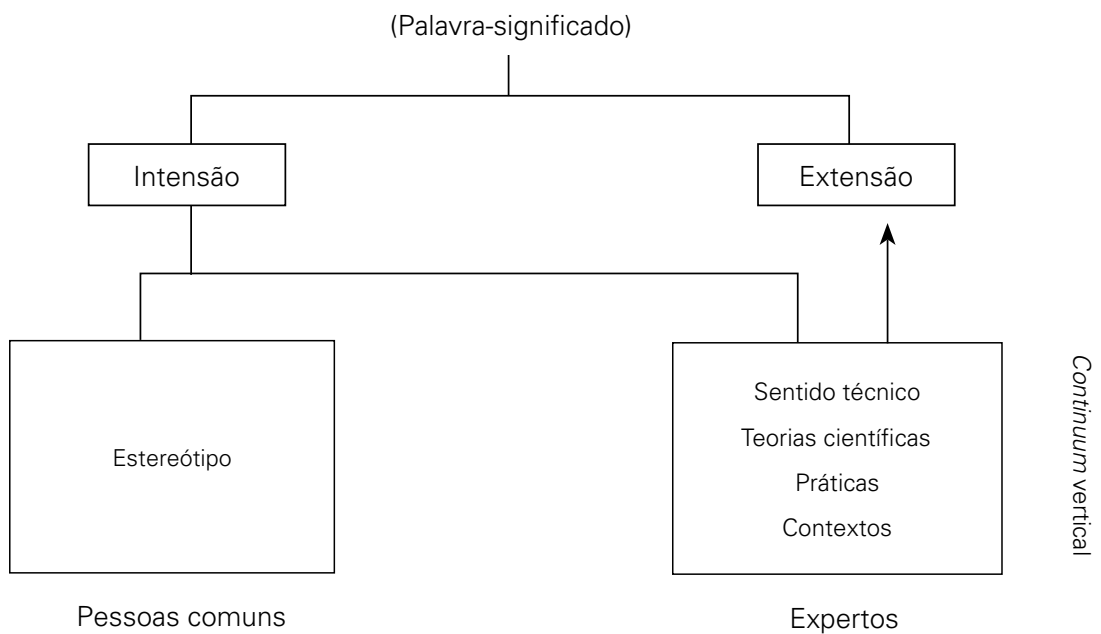

Continuum horizontal

A palavra-significado de um termo tem dois componentes: intensão e extensão; intensão é uma propriedade inerente ao termo, que é fixada em todas as coisas que a possuem: a intensão do signo "vermelho" é sua propriedade de avermelhamento; extensão refere-se à classe de entidades a que o termo se aplica: a extensão do termo "rosas vermelhas" é a classe de todas as rosas vermelhas existentes ou possíveis. Apreender a extensão de um termo não é uma tarefa simples e requer, como observa o autor, que conheçamos o mundo em nossa volta. Há outro aspecto importante apontado pelo autor: quando expertos usam, por exemplo, o termo "eletricidade", é no sentido técnico que 
eles pretendem demonstrar, num contexto relevante e compartilhado, certos conhecimentos e habilidades; mas isto não implica que todos possuam as mesmas qualificações: o know-how técnico "é um bem posicional, no sentido de que os benefícios a serem obtidos dele dependem crucialmente de outras pessoas terem certas habilidades complementares" (ibid., p. 190).

Conforme a Figura 1, intensão está subdividida em estereótipos, que pertencem às pessoas comuns, e sentido técnico, possuído pelos expertos, estabelecendo-se, entre ambos, um continuum de sentidos. A ideia de estereótipos está associada a fatos essenciais, que um indivíduo, numa comunidade linguística, deve aprender, simplesmente por ser um de seus membros. O estereótipo de água é sua coloração, transparência, função de matar a sede etc., mas nem todas as pessoas sabem ou precisam saber a composição química da água: este conhecimento requer sentido técnico que, por sua vez, tem vários níveis, envolvendo diferentes tipos de expertos. Como indicado, os estereótipos não podem determinar a extensão isoladamente, mas só em conjunto com o sentido técnico; além disso, as pessoas comuns vão depender de um canal de comunicação, e da autoridade dos expertos para tanto. O significado não é exaurido nem por sua intensão, nem por sua extensão, mas por ambos, porque o mesmo grupo de indivíduos não possui completamente este significado, que está, ao invés disso, dividido entre eles.

A hipótese da divisão do trabalho linguístico nos ajuda a ver o significado sob uma nova luz. Somente agora, com o componente social do significado completamente reconhecido, podemos ver porque o significado não é uma entidade psicológica possuída por cada indivíduo. [...] É a cooperação social que é essencial ao compartilhamento, não a presença de um estado psicológico similar (ibid., p. 184).

A análise da relação de interdependência entre leigos e especialistas, a exemplo do plano adotado por Bhargava, poderia tomar caminho metodológico. Vamos, aqui, adotar uma abordagem da teoria sociológica. Não é nosso propósito, neste estudo, prover um survey sobre inumeráveis teorias que disputam este tema. Ao contrário: vamos focar a ideia da modernidade reflexiva, elaborada por Anthony Giddens. Como discutido por Giddens, Ulrich Beck, Scott Lash, modernidade reflexiva é uma tentativa teórica, que visa caracterizar amplas tendências de mudanças sociais no mundo contemporâneo (Beck et al.,1997).

\section{Modernidade reflexiva}

Antes de iniciarmos a discussão propriamente dita sobre o tema em questão, vamos descrever brevemente alguns elementos da teoria da estruturação proposta por Giddens, e primeiramente publicada em 1984. Estes fundamentos ser-nos-ão úteis à compreensão da análise que se segue, sobre a tese da modernidade reflexiva.

A teoria da estruturação baseia-se na premissa de que o dualismo de "estru- 
tura" e "agência humana", objetivismo e subjetivismo, enraizado na teoria social, precisa ser reformulado como dualidade: não deve haver predominância da dimensão social, nem da experiência do ator individual, mas interação e implicação de uma na constituição da outra, cujo domínio básico é a prática social, continuada no espaço e tempo. A teoria da estruturação situa, como seu centro, o conceito de prática social, sendo definido através da reformulação dos conceitos de agente, agência, ação, poder, estrutura, sistema e espaço-tempo.

Todos os agentes sabem acerca do que fazem e por que o fazem. Sua cognoscitividade como agentes está largamente contida na consciência prática, significando que possuem considerável conhecimento das condições e consequências do que fazem em suas vidas cotidianas. Estas ações do dia a dia são rotinizadas e automáticas, sendo a consciência prática uma característica central da vida social. Os agentes também são capazes de descrever, em termos discursivos e quando solicitados, a racionalização de sua ação. Esta consciência discursiva significa que o agente pode, explicitamente, expressar uma atividade em relação a um corpo de conhecimento, opinião ou crítica. Uma característica da ação humana, que envolve tanto a consciência prática quanto discursiva, é o monitoramento reflexivo da ação: os agentes monitoram rotineiramente, tanto o fluxo de suas atividades - e esperam que os outros o façam -, quanto os aspectos sociais e físicos dos contextos em que se movem. Há, também, os motivos inconscientes da ação, que são importantes; mas não necessariamente acessíveis à consciência.

Agência refere-se a fazer: conecta-se à prática. Não é uma série de eventos discretos, mas um fluxo, na medida em que se relaciona à capacidade das pessoas em realizar coisas. Entretanto, é relevante falar de agência somente quando o agente racionaliza e reflete sobre a ação, através da consciência discursiva. Giddens parte da suposição que o agente humano é capaz de intervir no mundo, ou abster-se de tal intervenção. Isto significa que o agente tem, potencialmente, o poder de agir diferentemente. Agir é exercer o poder, envolvendo logicamente o último "no sentido de capacidade transformadora" (Giddens, 2003, p. 17). Sistema e estrutura são distintos. Sistemas são práticas sociais — relações entre agentes ou coletividades — que são reproduzidas ao longo do tempo e do espaço, das quais emerge a padronização das relações sociais. Diferentemente, estrutura é caracterizada pela ausência da agência, constituindo-se de recursos e regras que os agentes utilizam para a produção e reprodução da vida social. Recursos e regras: os primeiros estão envolvidos na geração de poder, manifestando-se, quer no domínio humano sobre a natureza (recursos alocativos), quer no domínio de alguns agentes sobre outros (recursos autoritários); regras subentendem procedimentos metódicos, significados e normas de interação social. Desta forma, estrutura não é algo externo à ação humana, ou análoga "às vigas mestras de um edifício", mas "traços mnêmicos orientando a conduta dos agentes humanos dotados de capacidade cognitiva" (ibid., p. 20). Finalmente, a definição-chave da teoria da estruturação - dua- 
lidade da estrutura: "as propriedades estruturais de sistemas sociais são, ao mesmo tempo, meio e fim das práticas sociais" (ibid., p. 30).

$\mathrm{O}$ trabalho de Giddens tem-se concentrado em temas relevantes às sociedades modernas. Em primeira aproximação, associada a um período de tempo e a uma localização geográfica inicial, modernidade "refere-se a estilo, costume de vida ou organização social, que emergiram na Europa a partir do século XVII e que, ulteriormente, se tornaram mais ou menos mundiais em sua influência" (Giddens, 1991, p. 11). A reflexibilidade do agente, da maneira como foi definida na teoria da estruturação, é característica definidora de toda ação humana. Este não é o sentido de "modernidade reflexiva", que está especificamente relacionado à época mais recente, "marcada pela radicalização e globalização dos traços básicos da modernidade", período este comumente denominado, pelo autor, de alta modernidade, modernidade tardia ou sociedade pós-tradicional.

\section{Reflexibilidade institucional}

Segundo o autor, a principal diferença entre modernidade e formações sociais tradicionais, é o dinamismo engendrado por três processos: primeiro, a separação de tempo e espaço, tornando possível articular relações sociais através de intervalos indeterminados do espaço-tempo. Processos tecnológicos "encurtam" o tempo e o espaço, criando um ambiente social global, e propiciando o zoneamento temporal e espacial preciso. "A organização social moderna supõe a coordenação precisa das ações de seres humanos fisicamente distantes; o quando destas ações está diretamente conectado ao aonde, mas não, como em épocas pré-modernas, pela mediação do lugar" (Giddens, 2002, p. 23).

O segundo processo - desencaixe - está intimamente vinculado aos fatores envolvidos na separação do espaço e tempo, e significa o descolamento da atividade social dos contextos locais, reorganizando as relações sociais através de grandes distâncias tempo-espaciais. Há dois mecanismos de desencaixe - fichas simbólicas e sistemas especializados - que, tomados em conjunto, são chamados de sistemas abstratos: o primeiro são os meios de troca que criam mediações abstratas entre indivíduos, sendo o dinheiro seu paradigma. "O dinheiro põe entre parênteses o tempo (porque é um meio de crédito) e também o espaço (pois o valor padronizado permite transações entre uma infinidade de indivíduos que nunca se encontraram fisicamente)" (ibid., p. 24); o segundo se refere a sistemas de conhecimento especializado, ou competência profissional - redes de transporte e comunicação, instituições sociais e políticas, mídia, peritos etc. - , sendo responsáveis pela organização de grandes áreas nos ambientes material e social em que vivemos hoje. "Os sistemas especializados põem entre parênteses o tempo e o espaço, dispondo de modos de conhecimento técnico que têm validade, independente dos praticantes e clientes que fazem uso deles" (ibid., p. 24).

Para o autor, o funcionamento dos sistemas abstratos depende essencial- 
mente da confiança. Mas confiança, adverte o autor, não é simplesmente como a crença que resulta de decisões baseadas em inferências indutivas a partir de tendências passadas, ou de alguma experiência passada supostamente relevante para o presente. Confiança está relacionada à "crença em pessoas ou sistemas abstratos, conferida com base em um 'ato de fé' que põe entre parênteses a ignorância ou a falta de informação" (ibid., p. 221).

A terceira influência que caracteriza o dinamismo da modernidade é a reflexibilidade, referindo-se "à suscetibilidade da maioria dos aspectos da atividade social, e das relações materiais com a natureza, à revisão intensa, à luz de novo conhecimento ou informação" (ibid., p. 26). Como observa o autor, a alteração das práticas sociais, à luz de descobertas sucessivas, não caracteriza unicamente a modernidade, nem mesmo a adoção do novo por si só, mas a suposição da reflexibilidade indiscriminada: "os indivíduos devem se acostumar a filtrar todos os tipos de informação relevantes para as situações de suas vidas, e atuar rotineiramente com base nesse processo de filtragem" (Giddens, 1996, p. 15). Esta reflexibilidade, associada ao dinamismo da vida social e "introduzida na própria base da reprodução do sistema", caracteriza a modernidade, e foi denominada, por Giddens, de reflexibilidade institucional.

A modernização reflexiva tem suas origens nas profundas modificações sociais trazidas pelo impacto da globalização, mudanças na vida cotidiana e pessoal, e o surgimento de uma sociedade pós-industrial. "A globalização trata efetivamente da transformação do espaço e do tempo. Eu a defino como ação a distância, e relaciono sua intensificação, nos últimos anos, ao surgimento da comunicação global instantânea e ao transporte em massa" (Giddens, 1996, p. 13).

É duvidosa, segundo Giddens, a visão iluminista de que a crescente informação sobre os mundos social e natural traria um controle cada vez maior sobre eles. Isto não quer dizer que a vida social presente é inerentemente mais arriscada que antes, mas relaciona-se à forma como tanto leigos, quanto especialistas, organizam o mundo social. Se é verdade que a modernidade reduz o risco geral de certas áreas (saúde, habitação, transporte etc.), também introduz, dado o caráter globalizado dos sistemas sociais, outros tipos de risco jamais imaginados (guerras maciçamente destrutivas, catástrofes ecológicas, colapso econômico global etc.). Se, por um lado, a modernidade é constituída por e através de conhecimento reflexivamente aplicado, por outro, a vida tornou-se muito mais aberta e contingente.

Em condições de modernidade, o mundo social nunca pode formar um meio ambiente estável em termos de entrada de conhecimento novo sobre seu caráter e funcionamento. O conhecimento novo (conceitos, teorias, descobertas) não torna simplesmente o mundo social mais transparente, mas altera sua natureza, projetando-a para novas direções (Giddens, 1991, p. 153). 


\section{Reflexibilidade do eu}

Giddens enfatiza que globalização não significa, apenas, o desenvolvimento de vastas redes econômicas, políticas e culturais: atividades e experiências, locais e pessoais, são profundamente moldadas pelos processos constitutivos de globalização. A vida cotidiana é crescentemente relacionada a eventos que acontecem globalmente e, cada vez mais, mediada pelos sistemas remotos de comunicação. "A globalização não é o mesmo que o desenvolvimento de um 'sistema mundial', e não está simplesmente 'aí fora' - tendo a ver com influências de grande alcance. Ela é também um fenômeno 'aqui dentro', diretamente ligado às circunstâncias da vida local” (ibid., p. 96). Milhões de comunidades, unificadas pelos costumes, crenças e práticas, transcendem os territórios do sistema de Estados-nação; religião é um exemplo, assim como comunidades virtuais mediadas pela internet.

Segundo o autor, é crucial, à sociedade contemporânea, que tradições tenham sido questionadas e problematizadas; pois, dificilmente, poderiam perdurar ações sociais baseadas somente na tradição. Assim sendo, reflexibilidade significa questionamento e subversão da tradição, implicando que esta não pode mais prover um conjunto firme de normas e crenças, que sejam usadas para criar confiança. A sociedade pós-tradicional é uma sociedade em que as convenções sociais são, ativa e conscientemente, criadas e renegociadas, ao invés de dadas, aceitas e inerentemente autoritárias. Mas isto requer considerações reflexivas, rompendo com o inquestionável status das premissas da tradição, que são transmitidas como verdades, através de rituais. Numa "sociedade globalizante, culturalmente cosmopolita, as tradições são colocadas a descoberto: é preciso oferecer-lhes razões ou justificativas" (Giddens, 1996, p. 14). Nesse sentido, tradição torna-se destradicionalizada. Destradicionalização não vincula o desaparecimento da tradição, mas sua incorporação reflexiva na sociedade moderna. Para Giddens, a sociedade pós-tradicional é criada, e reproduzida, na prática social; isto é: em interações recíprocas entre ações dos indivíduos e instituições sociais. Instituições sociais e estruturas, são os meios e fins das ações dos agentes. Consequentemente, a globalização das instituições é somente uma dimensão da problemática da modernidade. Outro aspecto se relaciona às transformações da vida cotidiana, e às modificações da intimidade e personalidade que este processo engendra. Além da reflexibilidade institucional, há que se considerar a reflexibilidade do eu:

As influências globalizadoras tendem a esvaziar os contextos locais de ação, que têm de ser reflexivamente reordenados por aqueles que foram afetados - embora esses reordenamentos, por sua vez, também afetem a globalização. [...] O self torna-se um projeto reflexivo [...]. Os indivíduos não podem se contentar com uma identidade que é simplesmente legada, herdada, ou construída em um status tradicional. A iden- 
tidade de uma pessoa necessita, em grande parte, ser descoberta, construída, sustentada ativamente (ibid., , p. 97).

A reflexibilidade do eu é contínua, e tudo penetra. A cada momento, ou pelo menos a intervalos regulares, o indivíduo é instado a autointerrogar-se em termos do que está acontecendo (Giddens, 2002, p. 75).

Nas condições de modernidade, os sistemas abstratos, entendidos como mecanismos de desencaixe, permeiam todos os aspectos da vida social, tornando inevitável que a apropriação regular de conhecimento especializado substitua a tradição. Seja uma nova dieta alimentar, recomendações de investimento, mapeamento de DNA, tantas outras, "a informação produzida por especialistas (incluindo o conhecimento científico) não pode mais ser totalmente confinada a grupos específicos, mas passa a ser interpretada rotineiramente e a ser influenciada por indivíduos leigos no decorrer de suas ações cotidianas" (Giddens, 1996, p. 15). Evidentemente, há inumeráveis formas de conhecimento diferenciado, e todos os tipos se apoiam sobre a divisão de trabalho especializado. Além disso, qualquer especialista detém uma parte ínfima do conhecimento e habilidade disponíveis, sendo, em última instância, um leigo em relação ao conjunto de possibilidades. Sobre o impacto destes sistemas abstratos em nossa vida, Giddens nos diz que "As mudanças revolucionárias de nosso tempo não estão acontecendo tanto no domínio da política ortodoxa quanto ao longo das fissuras da interação entre as transformações locais e globais" (ibid., 111). Como recorrentemente observamos, a maioria das áreas da atividade social vem sendo governada por decisões que requerem algum tipo de conhecimento especializado. Isto poderia, a princípio, intensificar a dependência do conhecimento perito sobre novas opções de escolha que se abrem. Mas,

Esta desqualificação não é simplesmente um processo em que especialistas técnicos se apropriam do conhecimento cotidiano (uma vez que muitas vezes há características imponderáveis ou ardentemente disputadas em seus campos de especialização); e nem é um processo unidirecional, porque a informação especializada, como parte da reflexibilidade da modernidade, é de uma forma ou de outra constantemente apropriada pelos leigos (Giddens, 2002, p. 27).

Ou seja: estamos diante de um processo de mão dupla, que envolve novas formas de liberdade e novas formas de dependência. Em geral, "seja na vida pessoal ou em meios sociais mais amplos, processos de reapropriação e de acesso ao poder se misturam à expropriação e à perda" (Giddens, 2002, p. 14).

\section{Dimensão social de expectativa}

Para Giddens, a vida social é constituída através da prática social, e sua grande ambição, ao formular a teoria da estruturação, foi justamente defini-la, 
enraizando-a nos conceitos de agente, agência, estrutura etc.: i) todo agente tem cognoscitividade e reflexibilidade, que se manifestam, principalmente, na consciência prática; ii) a maioria das práticas diárias não é diretamente motivada, mas prática rotinizada; iii) o agente tem, potencialmente, capacidade transformadora (poder); iv) agência refere-se a fazer; v) as propriedades estruturais de sistemas sociais são, ao mesmo tempo, meio e fim das práticas sociais; vi) estrutura não deve ser equiparada a restrição, mas é, sempre e simultaneamente, restritiva e facilitadora. Assim, o grande volume de conhecimento dos agentes é, em sua maioria, de caráter mais prático que teórico; além disso, "não faz sentido tratar a consciência prática como exaustivamente constituída por convicções ou crenças propositivas [...]. A cognoscitividade incorporada às atividades práticas que constituem a maior parte da vida cotidiana, é uma característica constitutiva (juntamente com o poder) do mundo social" (Giddens, 2003, p. 106). Noutros termos: grande parte do conhecimento é social; pressupõe e é adquirido, pelos agentes, através da prática; ipso facto, as crenças. Analogamente, expectativas, entendidas como crenças sobre acontecimentos futuros.

As práticas sociais são práticas reflexivas, continuamente examinadas e modificadas à luz de novo conhecimento e informação, trazendo certas particularidades à dimensão social de conhecimento e crença. Há crescente interconexão e tensão entre conhecimento leigo e conhecimento especializado: de um lado, a proliferação e estreitamento das áreas de especializações, tornam cada vez menor, em termos relativos, o campo de competência de qualquer indivíduo - todos somos leigos e crescentemente dependentes de expertos e sistemas especializados; de outro, a acessibilidade às habilidades e informações especializadas "está em princípio disponível para qualquer um, desde que tenha os recursos, tempo e energia para adquiri-la" (Giddens, 2002, p. 35).

Segundo Giddens, o funcionamento de sistemas especializados depende, essencialmente, da confiança, vista como crença no sentido de um "ato de fé", na credibilidade de uma pessoa ou sistema e, via de regra, rotineiramente incorporada à continuidade das atividades cotidianas: não são decisões de foro íntimo quando seguimos algum tratamento médico, assumimos a existência de outras galáxias (quem já viu?) ou que a inflação vai diminuir (quem já calculou?); entretanto, confiança "é muito menos um salto para o compromisso do que uma aceitação tácita de circunstâncias, nas quais outras alternativas estão amplamente descartadas"; mas isto não significa passividade e, sim, "uma questão de cálculo de vantagem e risco" (Giddens, 1991, pp. 88, 93).

Outra particularidade da dimensão social de conhecimento e crença na modernidade é o papel central exercido pela mídia na mediação da experiência humana: em escala cada vez mais global e instantânea, os meios de comunicação criam novas formas de ação e interação, deslocando as relações sociais de contextos locais. Nesta perspectiva, a apropriação de conhecimento especializado se realiza, em grande medida, separada das relações estabelecidas pela interação face a face. $\mathrm{Na}$ longa sequência até a mídia eletrônica global 
dos dias de hoje, recordemos que os primeiros livros eram feitos à mão, sobrevindo a invenção de Gutenberg, o telégrafo, o telefone, rádio, televisão etc.; a prevalência da experiência transmitida através da mídia, observa Giddens (ibid., p. 82), é uma das influências marcantes da pluralidade de escolhas que confronta os indivíduos no contexto da modernidade. Por um lado, a justaposição de grande número de ambientes segue na direção da diversificação e fragmentação; por outro, na superação de barreiras. "Como resultado, a ligação tradicional entre ambiente físico e situação social foi solapada; situações sociais que vêm pela mídia constroem novas semelhanças - e diferenças entre formas pré-construídas da experiência social" (ibid., p. 83).

Em sua abordagem sociológica da mídia, Thompson (2002) argumenta que modernidade é inseparável do caráter mundano da atividade receptiva: a recepção dos produtos da mídia deveria ser vista "como uma atividade de rotina, no sentido de que é uma parte integrante das atividades constitutivas da vida diária" (ibid., p. 43). Além de atividade situada e de rotina - observa o autor - a recepção é uma realização especializada, e vai depender de habilidades e competências, que são extremamente diversas entre os indivíduos. id., p. 45).

Ao analisar os efeitos que os meios de comunicação produzem na vida das pessoas, o autor toma, como ponto de partida, visão aderente à modernidade reflexiva, em relação à natureza do eu, e à experiência cotidiana num mundo mediado. Nas sociedades modernas, o processo de formação do eu se torna mais reflexivo, e mais depende dos próprios indivíduos, na construção de suas identidades. A interação mediada entre conhecimento local e "conhecimento não local" não destrói a conexão entre a formação do eu e o local compartilhado, na medida em que o processo de apropriação está sujeito aos interesses, habilidades e recursos dos receptores. Segundo o autor, a formação do eu torna-se mais e mais dependente do acesso às formas mediadas de comunicação, tendo impacto profundo no processo de autoformação: "O conhecimento técnico é gradualmente separado das relações de poder estabelecidas pela interação face a face [...]. Os horizontes de compreensão dos indivíduos se alargam; [...] A mídia se torna, nos termos de Lerner, um multiplicador da mobilidade" (ibid., p. 184).

\section{Conhecimento econômico}

Assuntos econômicos tendem, cada vez mais, a se alargar na consciência prática. Se, por um lado, atividades de rotina, como ter conta bancária, fazer aplicações financeiras, contrair empréstimos e financiamentos etc., subentendem domínio prático por parte dos leigos acerca dos conceitos econômicos de "capital", "juros" e "investimentos", outros temas, que até muito recentemente eram de interesse exclusivo de especialistas, vão se incorporando à vida cotidiana de todos nós. Isto é parte do sentido básico da reflexibilidade: nunca podemos estar seguros que determinado conhecimento não será revisado; na medida em que o ambiente econômico está constantemente sendo alterado e 
novas experiências vão sendo acumuladas, vai-se reformulando o conhecimento econômico.

Em relação às expectativas econômicas, há uma gama de variáveis comumente analisadas: entre as mais tradicionais, estão os índices de desemprego, inflação e renda. A relevância e interdependência de indicadores macroeconômicos, estabelecidas na consciência prática, vão depender do contexto; mas estão sempre ancorados num determinado conhecimento econômico. Relevância implica maior visibilidade, enquanto interdependência sinaliza ações e consequências. Numa política de metas de inflação, a expectativa desta variável é evidentemente crucial: se a projeção é de alta, determinado esquema de raciocínio poderia sinalizar aumento de juros; mas, também, como resultado, elevação de desemprego.

Entretanto, a credibilidade da apuração, análise e projeção de variáveis macroeconômicas, é inseparável do conhecimento especializado, que se forma em torno de uma rede de expertos, com diferentes habilidades e ocupações, compartilhando métodos e informações relevantes. A racionalidade do conhecimento produzido por especialistas subentende negociação social, que se estende inclusive aos métodos e informações utilizados. Porém o que está em jogo não é a infalibilidade desse conhecimento, mas sua legitimidade e autoridade. Nesse contexto, corre-se o risco de especialistas se confundirem com um agente representativo, técnica e socialmente falando. ${ }^{3}$

Por outro lado, decisões econômicas que não se pautem pelo conhecimento especializado, podem ser danosas ao agente. Vejamos um exemplo: dois trabalhadores decidem pedir aumento de salário; o primeiro argumenta que o IPCA aumentou $10 \%$ nos últimos 15 meses, mas seu salário continua inalterado; o segundo alega a mesma situação mas, baseado numa planilha de custos de suas despesas, sustenta que a inflação foi $30 \%$. Não cabe aqui discutir se um ou ambos obterão aumento de salário, mas os desdobramentos dos respectivos argumentos: por ter-se baseado num índice de inflação socialmente acordado, há pouco que se comentar sobre o primeiro. Quanto ao segundo, é de se esperar que seu superior vá buscar convencê-lo de que seu índice de inflação não pode ser usado como referência; se o trabalhador não se convencer, manterá seu argumento equivocado em situações posteriores.

\section{CONCLUSÃO}

Concluindo, sugerimos que a expectativa econômica é conhecimento socialmente construído a partir das expectativas de expertos, estando estas, em grande medida, publicamente disponíveis através da mídia, e sendo rotineiramente incorporadas pelos leigos, ainda que de maneira diferenciada, à cons-

${ }^{3}$ Ver Bresser-Pereira (2001). 
ciência prática. Porém, nada impede - e claramente acontece — que as pessoas divirjam, ignorem ou até desconheçam o significado e implicação destas grandezas em suas vidas.

Implicitamente à conclusão acima, que vamos denominá-la por hipótese de expectativas socialmente construidas (HESC), dois fatores são determinantes na formação de expectativas do agente: embora expectativas econômicas de especialistas sejam socialmente supridas, têm que ser individualmente apropriadas para que sejam utilizadas; em segundo lugar, são necessários arranjos sociais e rotinas de interação entre agente e informação especializada: o agente pode informar-se involuntariamente através de seus afazeres cotidianos (conversas, noticiários etc.), ou fazer buscas voluntárias junto a fontes especializadas. O primeiro fator está relacionado ao conhecimento; o segundo, à rede social em que o agente está inserido.

Arrow (1962) foi um dos primeiros economistas a considerar que o conhecimento poderia ser incluído em modelos econômicos como variável endógena, quando examinou os efeitos de learning by doing. Esta hipótese supõe que o trabalhador aprende através da experiência, tendo, como consequência, economia de escala ao longo do tempo. Posteriormente, novos modelos de crescimento endógeno (Romer, 1986; Lucas, 1988), incorporaram o papel da educação e do investimento em pesquisa. A atração por estes modelos foi manter a estrutura da economia neoclássica e, ao mesmo tempo, tentar eliminar uma questão conceitual: a importância do conhecimento na análise econômica, pressuposto central para economistas como Adam Smith, Hayek, Schumpeter, entre outros.

O contexto temporal-espacial das práticas sociais é reconhecidamente negligenciado na teoria social. ${ }^{4}$ Uma linha de pesquisa contemporânea para tratar deste assunto, gravita em torno da abordagem e conceitualização de redes. Para Castells (2001, p. 497), cuja obra, segundo Giddens, é comparável à Economia e Sociedade de Max Weber, "Redes constituem a nova morfologia social de nossas sociedades, e a difusão da lógica de redes modifica de forma substancial a operação e os resultados dos processos produtivos e de experiência, poder e cultura”.

Sob a HESC, as expectativas dos agentes, em modelos macroeconômicos, não são determinadas a partir de equações do próprio modelo. Postular que os agentes formam suas expectativas solucionando o modelo macroeconômico, é reduzir as expectativas daqueles à do próprio modelo, quando a questão-chave é justamente entender as expectativas dos agentes. De outra forma: é o modelo que pressupõe expectativa do agente; não o contrário. Isto não impede - e claramente acontece - , que agentes incorporem métodos e procedimentos de modelos econômicos e, reciprocamente, que modelos se aprimorem com as práticas dos agentes. Mas há uma implicação metodológica importante: em-

\footnotetext{
${ }^{4}$ Giddens (1979), Krugman (1991), Abbott (1977), Raftery (2000).
} 
bora interdependentes, podem demandar métodos distintos, se buscarmos bases plausíveis para uma teoria de formação de expectativa. ${ }^{5}$

As expectativas racionais têm-se constituído, nos últimos trinta anos, na abordagem dominante de pensar a dinâmica e avaliação de políticas na economia; mas vários problemas empíricos e teóricos foram igualmente identificados. Em razão destes problemas, vários autores têm proposto relaxar algumas de suas premissas (vide primeira seção). Entretanto, não é somente questão de acomodar, teoricamente, as hipóteses fixadas sobre formação de expectativa - como parecem sugerir os esforços daqueles autores -, mas, principalmente, justificar fundamentos epistêmicos daqueles pressupostos.

Conquanto concordemos com pós-keynesianos quando afirmam que até mesmo especialistas podem se deparar com incerteza fundamental em suas projeções, erram eles o alvo: a questão não é se expectativa corresponde a priori ou a posteriori à descrição do mundo real, mas que ela é construção social.

Finalmente cremos que nossa conclusão sobre formação de expectativa não se contrapõe à visão de Keynes. Vejamos nossa conclusão: expectativa econômica é conhecimento construído a partir da consciência discursiva de expertos, sendo rotineiramente incorporada pelos leigos, ainda que de maneira diferenciada, à consciência prática.

A importância da incerteza e expectativa no pensamento econômico de Keynes tem sido, há muito, reconhecida, embora sejam mais recentes os estudos que buscam interpretar esta ideia sob a luz de sua teoria lógica de probabilidades. Entretanto, é comum, entre comentadores de Keynes, admitir-se que a Teoria Geral nem sempre é suficientemente clara sobre este tópico. Também não podemos, embora não necessariamente, por causa da afirmação anterior, falar em consenso sobre o significado de incerteza e expectativa na análise de Keynes. De qualquer forma, quando examinamos a análise de expectativas na Teoria Geral, alguns pontos não podem passar despercebidos: i) a discussão está focada no comportamento dos empresários, havendo distinção entre expectativas de curto e longo prazo; ii) o papel da convenção, do estado de confiança e do paradigmático animal spirits na formação de expectativas.

O estado de confiança reflete a avaliação do empresário sobre a evidência disponível: "Nossas conclusões devem fundamentar-se, principalmente, na observação prática dos mercados e da psicologia dos negócios" (Keynes, 1985, p. 110). Mas "reconhecendo que nosso julgamento individual é sem valor, tentamos nos direcionar ao julgamento do resto do mundo, que é, talvez, melhor informado. [...] A psicologia de uma sociedade de indivíduos, onde cada um está tentando copiar os outros, leva ao que podemos, estritamente, denominar julgamento convencional" (Keynes, 1937, p. 214).

Sob a perspectiva da modernidade reflexiva, o funcionamento de sistemas

\footnotetext{
${ }^{5}$ Para uma discussão sobre objeto e método na teoria econômica ver Bresser-Pereira (2009).
} 
especializados depende essencialmente da confiança, vista como crença, no sentido de um "ato de fé" na credibilidade de uma pessoa ou sistema e, via de regra, rotineiramente incorporada à continuidade das atividades cotidianas. Entretanto, confiança "é muito menos um salto para o compromisso do que uma aceitação tácita de circunstâncias, onde outras alternativas estão amplamente descartadas" (Giddens, 1991, p. 88).

Sempre poderemos nos voltar para os expertos, mas eles próprios, muitas vezes, estão em desacordo sobre teorias e diagnósticos práticos. Supostamente, para o empresário keynesiano, tornar-se-ia urgente a ação do animal spirits.

\section{REFERÊNCIAS BIBLIOGRÁFICAS}

ABBOT, A. (1997) "Of time and space: The contemporary relevance of the Chicago School" Social Forces 75: 1149-82.

AGHION, P., FRYDMAN, R., STIGLITZ,J., WOODFORD, M. (2003) Knowledge, Information, and Expectations in Modern Macroeconomics. Princeton: Princeton University Press.

ARROW, K. (1962) "Economic implications of learning by doing", Review of Economic Studies 29: $155-173$.

(1994) "Methodological individualism and social knowledge", AEA Papers Proceedings, May, p. $1-9$.

BALL, L. (1994). "Credible disinflation with staggered price setting” American Economic Review LXXXIV: 282-289.

BECK, U., GIDDENS, A., LASH, S. (1997) Modernização Reflexiva: Política, Tradição e Estética na Ordem Social Moderna. Trad. Magda Lopes, Editora UNESP.

BHARGAVA, R (1992) Individualism in Social Science - Forms and Limits of a Methodology. New York: Oxford University Press.

BRESSER-PEREIRA, L. C. (2001) "Incompetência e confidence bulding por trás de 20 anos der quase estagnação da América Latina”. Revista de Economia Política, 21 (1), janeiro-março.

(2009) “Os dois métodos e o núcleo duro da teoria econômica”. Revista de Economia Política, 29 (2), abril-junho.

CALVO, (1983),"Staggered prices in a utility maximizing framework," Journal of Monetary Economics XII: 383-398.

CALVO, G., CELASUN, O., HUMHOF, M. (2003) “A theory of rational inflationary inercia”. em Aghion el ale (2003).

CARROL, C.D. (2003) "Macroeconomic expectations of households and professional forecasters", Quarterly Journal of Economics, 118 (1), February.

CASTELLS, M. (2001). A Sociedade em Rede (volume I). Trad. de R. V. Majer. São Paulo, Paz e Terra.

DAVIDSON, P. (1978) Money and the Real World. London: Macmillan.

(1982-3) "Rational expectations: a fallacious foundation for studying crucial decision-making processes”, Journal of Post-Keynesian Economics. 5: 182-198.

DOW, S., HILLARD, J. (1995). Keynes, Knowledge and Uncertainty. Aldershot, Edward Elgar.

EATWELL, J., MILGATE, M., NEWAN, P., eds. (1998) The New Palgrave: A Dictionary of Economics. Vol. 1-4. London: The Macmillan Press Limited.

EVANS, G. W., HONKAPOHJA, S. (2001) Learning and Expectations in Macroeconomics. Princeton: Princeton University Press.

FRYDAMAN, R., GOLDERG, M. M. (2003) “Imperfect knowledge expectations, uncertainty-adjusted uncovered interest rate parity, and exchange rate dynamics" in Aghion et al. (2003). 
GIDDENS, A. (1979), Central Problems in Social Theory. Action, Structure and Contradiction in Social Analysis, London: Macmillan.

(1991) As Consequências da Modernidade. Trad. Raul Fiker. São Paulo: Fundação Editora da UNESP.

(1996) Para Além da Esquerda e da Direita. Trad. Alvaro Hattnher. São Paulo: Fundação Editora da UNESP.

(2002) Modernidade e Identidade. Trad. Plínio Dentzien. Rio de Janeiro: Jorge Zahar Editor. (2003) A Constituição da Sociedade. Trad. Álvaro Cabral. São Paulo: Martins Fontes.

HACKING, I. (1975) The Emergence of Probability, Cambridge, Cambridge University Press.

HANSSON, B. (1998) "Stockholm School”, in Eatwell et al. (1998), vol.4.

KEYNES (1937) "The general theory of employment”, Quarterly Journal of Economics. February, 51: 209-223.

(1973) A Treatise on Probability. London: MacMillan.

(1985) A Teoria Geral do Emprego, do Juro e da Moeda. Trad. Mário R. da Cruz. São Paulo, Nova Cultural.

KRUGMAN, P. (1991) "Increasing returns and economic geography”, Journal of Political Economy, 99 (3): 483-499.

LAWSON, T. (1988). "Probability and uncertainty in economic analysis." Journal of Post-Keynesian Economics. 11: 38-65.

LUCAS, R. (1988), "On the mechanics of economic development", Journal of Monetary Economics 22: 3-42.

MANKIW, N.G. (2001). "The inexorable and mysterious tradeoff between inflation and unemployment”. Economic Journal 111(471): C45-61.

MANKIW, N.G., REIS, R. (2001). "Stick information versus stick prices: a proposal to replace the new Keynesian Phillips curve”, NBER Working Paper No. 8290.

MUTH, J.F. (1961) "Rational expectations and theory of price movements." Econometrica, July, 29: 315-335.

NELSON, R., WINTER, S. (1982), An Evolutionary Theory of Economic Change. Cambridge, MA: The Belknap Press.

PERLMAN, M., MCCANN, C. R. J.(1996). "Varieties of uncertainty” in Schmidt (1996)

POTTS, J. (2001). "Knowledge and markets". Journal of Evolutionary Economics 11(4): 413-31.

ROMER, P. (1986) 'Increasing returns and long-run growth', Journal of Political Economy 98(5): 1002-37.

ROSEMBERG, A. (1980) “Obstacles to the nomological connection of reasons and actions”, Philosophy of Social Science, 10: 79-91.

RAFTERY, A. E. (2000) "Statistics in sociology, 1950-2000". Journal of the American Statistical Association; 654-661.

SARGENT, J.T.(1995). Bounded Rationality in Macroeconomic. Oxford: Oxford University Press.

SIMS, C. A.(2001) "Implications of rational inattention". Journal of Monetary Economics, 50: 665-690.

SCHMDIT, C., ed. (1996) Uncertainty in Economic Thought, Londres: Edward Elgar.

TOMPSON, J.B. (2002) A mídia e a Modernidade: Uma Teoria Social da Mídia. Trad. Wagner de Oliveira Brandão. Petrópolis: Editora Vozes.

WEATHERFORD, R. (1982) Philosophical Foundations of Probability Theory. London: Routledge \& Kegan Paul.

WOODFORD, M. (2003) "Imperfect common knowledge and the effects of monetary policy" in Aghion (2003) et al. 